\title{
Characterization of Degradation and Failure Modes in Lithium-ion Cells
}

\author{
Quinn Horn and Kevin White
}

Exponent Failure Analysis Associates, Natick, Massachusetts, USA

A significant effort has been made to develop techniques that facilitate the understanding of degradation in lithium-ion cells. Among the most successful techniques is electrochemical impedance spectroscopy (EIS). When combined with ex situ characterization techniques (e.g. XRD, XPS, AES, Raman, FTIR, SEM/EDS and TEM), EIS has proven to be a powerful tool in understanding degradation mechanisms in lithium-ion cells.[1-6] The disadvantage of this approach is that the spatial relationship between the anode, separator and cathode is lost. In addition, these techniques only allow characterization of surfaces, so that the distribution of degradation reaction products, impurities and other species throughout the thickness of the electrodes cannot be studied.

A technique has been developed whereby the electrolyte and electrolyte-soluble species are extracted from a lithium-ion cell. The porosity of the cell can then be infiltrated with a polymer resin, after which the cell can be mechanically cross-section in any orientation. The cross-sectioned surface is then "polished" by specialized non-aqueous techniques. The resulting sample is stable in the air and in vacuum, making it convenient for a wide range of microscopic characterization techniques. In addition, thin sections $(\sim 100 \mu \mathrm{m})$ can be prepared of the cross-sectioned cells, enabling the use transmission micro X-ray diffraction techniques for crystallographic characterization at $10 \mu \mathrm{m}$ resolution. A photograph of the surface of a radially cross-sectioned cell shown in Figure 1 (top). The light microscope image in Figure 1 (bottom) shows the microstructure of the positive and negative electrodes in this cell.

In this presentation, the sample preparation technique will be reviewed and several examples of different degradation mechanisms will be shown. These examples will include laboratory studies where cells have been exposed to known abuse situations; for example, the cell shown in the SEM image in Figure 2 that was cycled under high-rate conditions and exhibits severe fracturing of cathode particles near the separator. Examples of degradation mechanisms in field-return cells will also be shown, such as the conductive separator growths and microshorting shown in the SEM image Figure 3.

\section{References}

[1] S.R. Narayanan, D.H. Shen, S. Suramoudi, A.I. Attia, and G. Halpert, Journal of the Electrochemical Society, 140 (7) (1993)

[2] R. Kostecki, J. Lei, F. McLarnon, J. Shim, and K. Striebel, Journal of the Electrochemical Society, 153 (4) A669-A672 (2006)

[3] R.W.J.M. Huang, F. Chung, and E.M. Kelder Journal of the Electrochemical Society, 153 (8) A1459-A1465 (2006)

[4] D.P. Abraham, E.M. Reynolds, P.L. Schultz, A.N. Jansen, and D.W. Dees, Journal of the Electrochemical Society, 153 (8) A1610-A1616 (2006)

[5] R.W.J.M. Huang, F. Chung, and E.M. Kelder, Journal of the Electrochemical Society, 153 (8) A1459-A1465 (2006) 
[6] J. Meyers, M. Doyle, R. Darling, and J. Newman, Journal of the Electrochemical Society, 147 (8) 2930-2940 (2000)

[7] G. Sikha, P. Ramadass, B.S. Haran, R. E. White, and B. Popov, Journal of Power Sources 122 67-76 (2003)

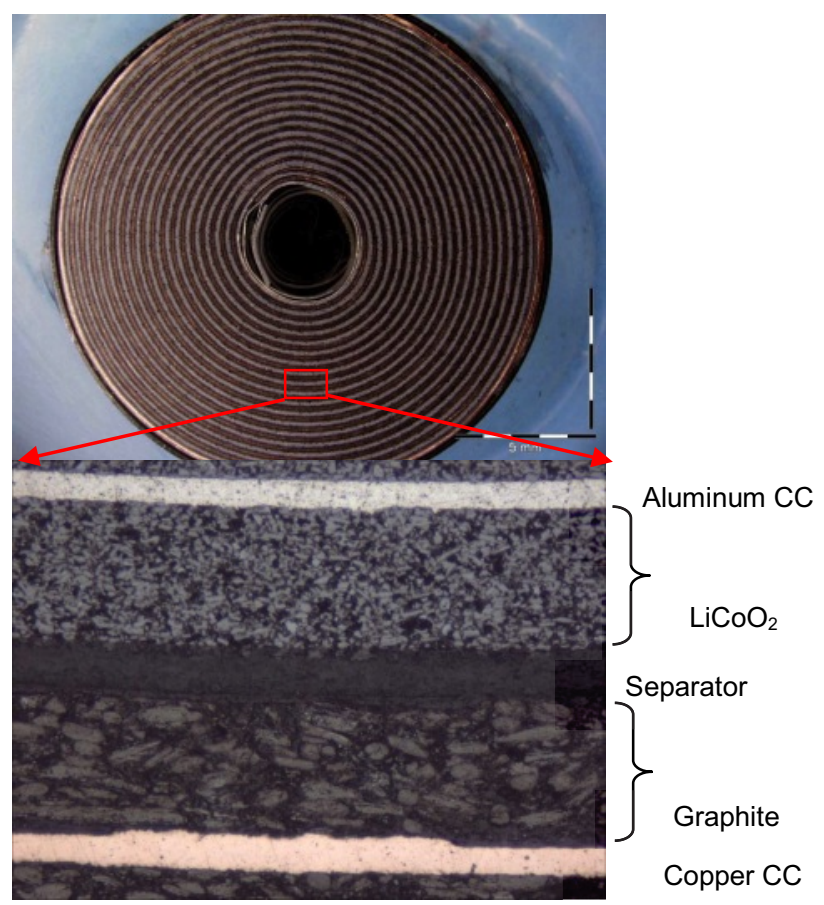

Figure 1. (top) photograph of the cross-section of an 18650 commercial lithium-ion cell; (bottom) light microscope image of the same cross-section at higher magnification showing the microstructure of the positive and negative electrodes.

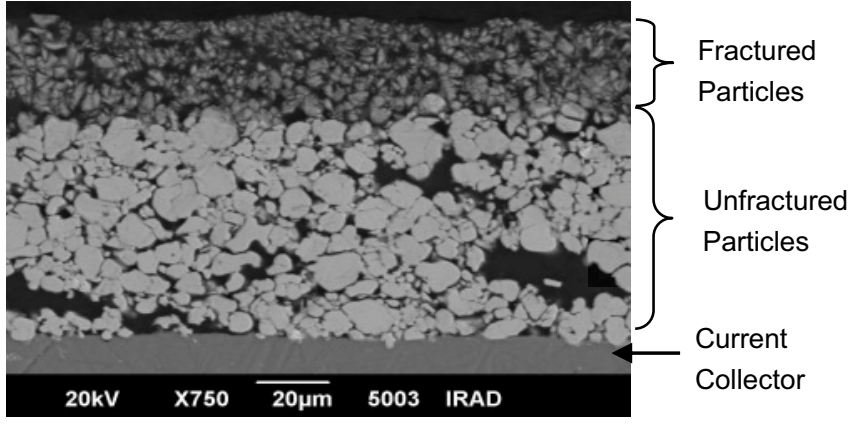

Figure 2. Back-scattered SEM image of severe $\mathrm{LiCoO}_{2}$ particle fracture in a lithium-ion cell cycled with high charge rates.

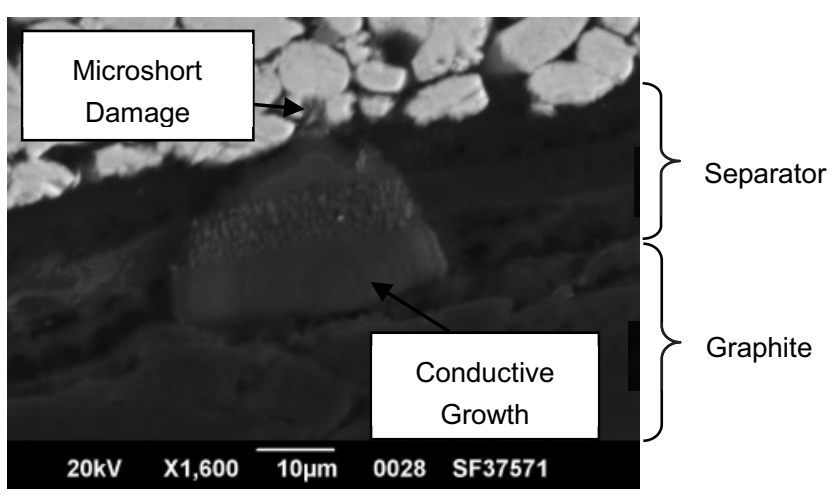

Figure 3. Back-scattered SEM image of a conductive growth in the separator of lithium-ion cell. The growth penetrated the separator and caused damage on the opposing cathode where shorting occurred. 